\title{
Estudos DFT e CASSCF da ligação de coordenação M-CO
}

\author{
Marina Pelegrini ${ }^{1}(\mathrm{PQ})^{*}$, Rafael M. $\operatorname{Madeira}^{2}(\mathrm{PG})$, Sérgio E. Galembeck $^{2}(\mathrm{PQ})$ \\ *marinamp@fab.mil.br \\ ${ }^{1}$ Divisão de Ensino, Academia da Força Aérea. Pirassununga - SP, Brasil. \\ ${ }^{2}$ Departamento de Química, Faculdade de Filosofia, Ciências e Letras de Ribeirão Preto, USP. Ribeirão \\ Preto - SP, Brasil. \\ Palavras-chave: HOMO-LUMO, COMPOSTOS DE COORDENAÇÃO, NBO, Fe, Co, Mn.
}

\section{Introdução}

Os efeitos tóxicos do gás $\mathrm{CO}$ no organismo são bem conhecidos, pois através de sua inalação ele se liga à hemoglobina, e como a afinidade do $\mathrm{CO}$ à hemoglobina é bem maior que a afinidade entre esta e o oxigênio molecular, o $\mathrm{CO}$ se liga preferencialmente às células do sangue impedindo o transporte de oxigênio para os tecidos. Entretanto, no século XX investigou-se a possibilidade do uso terapêutico da espécie CO [1]. Entre outras constatações, observou-se que pessoas em ampla variedade de doenças, apresentavam níveis de $\mathrm{CO}$ muito maiores que pessoas saudáveis, e que o $\mathrm{CO}$ era produzido endogenamente pelos organismos doentes. A possibilidade de $\mathrm{CO}$ como substância terapêutica foi testada positivamente em vários modelos com animais $[1,2]$. Dentro deste contexto, o design de um fármaco liberador de $\mathrm{CO}$ no organismo é uma questão que está sendo considerada. Com a sigla "CORMs" (Carbon Monoxide Releasing Moieties), uma das classes destes compostos são os complexos carbonílicos metálicos, numa variedade de complexos de carbonila de rutênio, ferro, manganês, cobalto, irídio e metais do grupo $6[2,3]$. Outros estudos recentes têm sido publicados a respeito de estruturas CORMs, tanto considerando compostos orgânicos [4], como também com compostos de coordenação M-CO bimetálicos [5].

O objetivo deste trabalho é investigar a ligação química nos complexos metálicos carbonílicos, compreendendo a interação entre $\mathrm{CO}$ e os metais como ferro, manganês e cobalto. Os estudos vão investigar as ligações quando se adiciona diferentes ligantes além do CO, como a multiplicidade e estados de oxidação do metal influenciam essas ligações, e como diferentes metais interagem com os ligantes.

\section{Metodologia}

As estruturas dos compostos de coordenação $M[\mathrm{CO}]_{6}^{2+} M[\mathrm{CO}]_{n}[\mathrm{H} 2 \mathrm{O}]_{m}^{2+}$ e

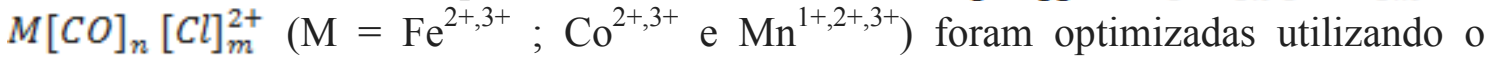
método DFT, BP86 e o conjunto de funções base def2tzvp. Também foram realizados cálculos CASSCF para atestar o caráter multiconfiguracional das funções de onda.

As ligações químicas nestes complexos e ainda outros com diferentes ligantes, serão analisadas por algumas das teorias de análise da densidade eletrônica, como NBO (Natural Bond Orbital) e métodos associados, QTAIM (Quantum Theory of Atoms in Molecules) e IQA (Interacting Quantum Atoms) e ELF (Electron Localization Function).

\section{Resultados e Discussão}

O CO é um ligante de campo forte, desta forma optou-se por inserir o $\mathrm{Cl}^{-}$como segundo ligante, por se tratar de um ligante de campo fraco, e assim analisar a influência na ligação química, inclusive se há um aumento na importância da descrição multiconfiguracional da função de onda.

Resultados preliminares demonstram que a inclusão do ligante $\mathrm{Cl}$ estabiliza estados de multiplicidade mais altas, o que se verifica também na diminuição do gap entre HOMO e LUMO. E, em geral a distância da ligação M-CO se torna maior quando estes ligantes estão presentes nos complexos. 
Quando se observa o comportamento dos comprimentos de ligação diante da inclusão de diferentes ligantes, há um aumento na distância $\mathrm{M}-\mathrm{CO}$ de 0.02 u.a. quando se acrescenta um ligante $\mathrm{Cl}$, e de até 0,05 u.a. quando são dois $\mathrm{Cl}$ em $\mathrm{Fe}[\mathrm{CO}]_{n}^{2+}$. Esta é a tendência observada também com as espécies $\mathrm{Mn}^{2+}$ e $\mathrm{Co}^{2+}$. A inclusão de moléculas $\mathrm{H}_{2} \mathrm{O}$ como ligantes não mostrou o mesmo comportamento, pois sua influência é bem menor.

A posição relativa dos ligantes influencia a interação entre as carbonilas e o metal, quando se adiciona dois ligantes $\mathrm{Cl}$ em posições adjacentes no octaedro, as ligações $\mathrm{M}$ $\mathrm{CO}$ em posição trans a estes ligantes são relativamente mais extendidas.

Quando se compara a influência do ligante sobre os orbitais moleculares $\mathrm{Fe}-\mathrm{C}$, a partir da visualização dos orbitais HOMO e LUMO, na presença do cloro, estes orbitais não apresentam contribuição de duas das ligações $\mathrm{Fe}-\mathrm{C}$, as quais são as maiores distâncias de ligação, enquanto que ao considerarmos o ligante $\mathrm{H}_{2} \mathrm{O}$, há um recobrimento sobre todas as ligações $\mathrm{Fe}-\mathrm{C}$, e todas as distâncias de ligação $\mathrm{Fe}-\mathrm{C}$ são iguais.

Cálculos CASSCF preliminares foram realizados para os complexos formados apenas com ligantes $\mathrm{CO}$, e estes apresentaram insignificante caráter multiconfiguracional, numa próxima etapa analisaremos como os diferentes ligantes influenciam na importância da descrição multiconfiguracional da função de onda.

\section{Referências}

[1] C. C. Romão, W. A. Blattler, J. D. Seixas, G. J. L. Bernardes, Chem Soc Rev 41, 3571 (2012).

[2] R. D Rimmer, A.E. Pierri, P. C. Ford, Coord Chem Rev 256,1509 (2012).

[3] S. V. C. Vummaleti, D. Branduardi, M. Masetti, M, de Vivo, R. Motterlini, A. Cavalli, Chem Eur J 18, 9267 (2012).

[4] X. Ji, B. Wang, Acc Chem Res 51, 1377 (2018).

[5] S. Pan, L. Zhao, H. V. R. Dias, G. Frenking, Inorg Chem XXXX, DOI:10.1021/acs.inorgchem.8b00851.. 